
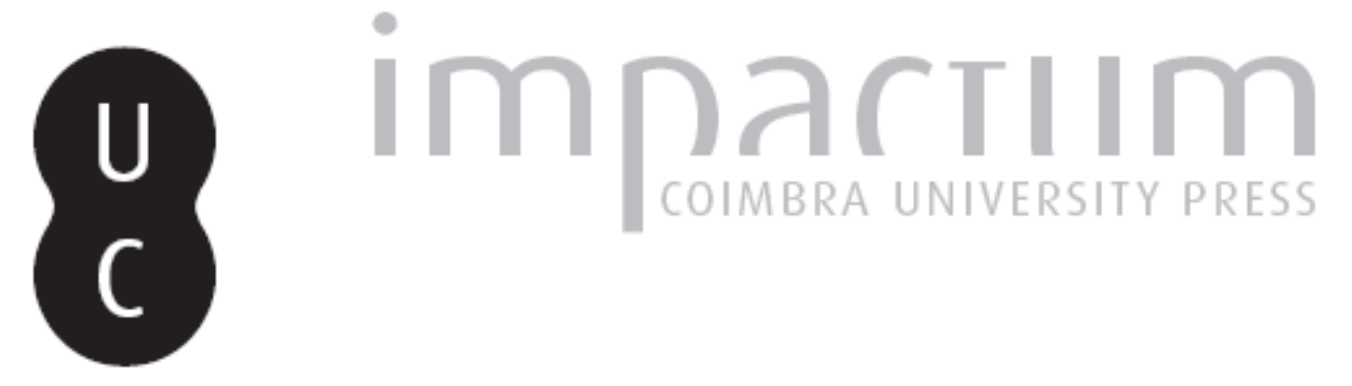

Unidades de conservação, legislação ambiental e a APA Petrópolis

Autor(es): $\quad$ Paiva, Julieta Laudelina de

Publicado por: Universidade Católica de Petrópolis

URL persistente:

URI:http://hdl.handle.net/10316.2/33859

DOI:

DOI:http://dx.doi.org/10.14195/2175-0947_2-1_2

Accessed : $\quad$ 26-Apr-2023 14:04:34

A navegação consulta e descarregamento dos títulos inseridos nas Bibliotecas Digitais UC Digitalis, UC Pombalina e UC Impactum, pressupõem a aceitação plena e sem reservas dos Termos e Condições de Uso destas Bibliotecas Digitais, disponíveis em https://digitalis.uc.pt/pt-pt/termos.

Conforme exposto nos referidos Termos e Condições de Uso, o descarregamento de títulos de acesso restrito requer uma licença válida de autorização devendo o utilizador aceder ao(s) documento(s) a partir de um endereço de IP da instituição detentora da supramencionada licença.

Ao utilizador é apenas permitido o descarregamento para uso pessoal, pelo que o emprego do(s) título(s) descarregado(s) para outro fim, designadamente comercial, carece de autorização do respetivo autor ou editor da obra.

Na medida em que todas as obras da UC Digitalis se encontram protegidas pelo Código do Direito de Autor e Direitos Conexos e demais legislação aplicável, toda a cópia, parcial ou total, deste documento, nos casos em que é legalmente admitida, deverá conter ou fazer-se acompanhar por este aviso.

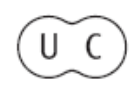



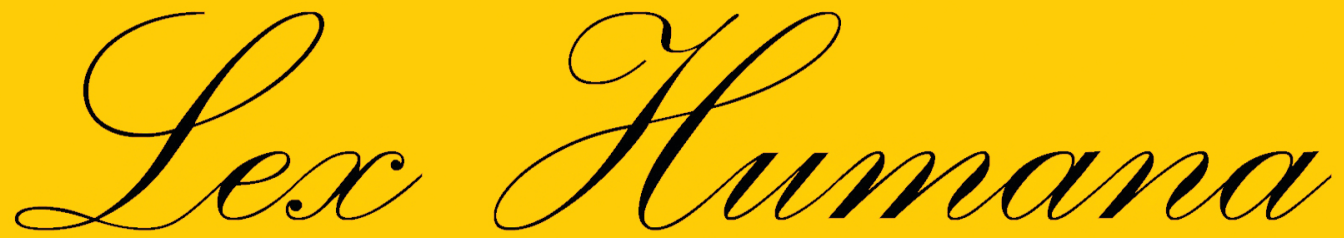

Revista do Programa de Pós-Graduação em Direito da UCP

ISSN(e) 2175-0947

Universidade Católica de Petrópolis Rua Benjamin Constant, 213 - Petrópolis - Centro CEP 25610-130

Tel: (24) 2244-4000 E-mail: lexhumana@ucp.br 


\title{
Unidades de Conservação, Legislação Ambiental e a APA Petrópolis
}

\author{
Dra. Julieta Laudelina de Paiva ${ }^{1}$
}

Resumo

As unidades de conservação são criadas com o objetivo de manter a diversidade biológica, proteger espécies ameaçadas de extinção, preservar e restaurar ecossistemas naturais. A Área de Proteção Ambiental da Região Serrana de Petrópolis - APA PETRÓPOLIS, primeira APA federal, foi criada por apresentar rica biodiversidade além de ter seus atributos naturais relativamente bem conservados. A população residente na APA Petrópolis está submetida ao cumprimento de várias determinações legais nos três níveis administrativos.

Palavras-chave: Unidades de conservação. Meio ambiente. Legislação ambiental

Abstract

Protected areas are created to keep biodiversity, protect endangered species, as well as preserve and restore natural ecosystems. The Environmental Protected Area of Petrópolis, called

1 Doutora em Meio Ambiente pela Universidade do Estado do Rio de Janeiro, PPG-MA (2010). Mestre em Ciência Ambiental pela Universidade Federal Fluminense - PGCA(1999). Bacharelado e Licenciatura Plena em Ciências Biológicas pela Faculdade de Humanidades Pedro II (1976). Especialização em Planejamento de Ensino (1986). Atualmente é Coordenadora da Pós-Graduação em Licenciamento Ambiental no Centro Universitário de Barra Mansa 
APA PETRÓPOLIS, located in the mountains of the State of Rio de Janeiro, was created because its rich biodiversity and relatively wellpreserved natural resources. People who live in that protected area are submitted to several environmental laws.

Keywords: Protected area. Environment. Environmental legislation.

\section{Introdução}

As unidades de conservação são criadas com o objetivo de manter a diversidade biológica, proteger espécies ameaçadas de extinção, preservar e restaurar ecossistemas naturais, promover o desenvolvimento sustentável, estimular a utilização de princípios e práticas de conservação da natureza, proteger paisagens naturais de grande beleza cênica, proteger e recuperar os recursos hídricos, promover a educação ambiental, valorizar econômica e socialmente a diversidade biológica. (BRASIL, Lei 9.985/2000, art. $4^{\circ}$ ).

\section{Unidades de Conservação}

A Lei 9.985 de 18 de julho de 2000 instituiu o Sistema Nacional de Unidades de Conservação (SNUC), e estabeleceu critérios e normas para a criação, implantação e gestão desses espaços territoriais protegidos.

De acordo como $\operatorname{artigo} 2^{\circ}$, inciso I, uma unidade de conservação é:

Espaço territorial e seus recursos ambientais, http://www.ucp.br/htmlljoomlaBR/lexhumanallexhumana.htm 
incluindo as águas jurisdicionais, com características naturais relevantes, legalmente instituído pelo Poder Público, com objetivos de conservação e limites definidos, sob regime especial de administração, ao qual se aplicam garantias adequadas de proteção. (BRASIL, Lei 9.985/2000).

$\mathrm{O}$ artigo $7^{\circ}$ desta lei divide as unidades de conservação em duas categorias, as unidades de conservação de proteção integral e as unidades de uso sustentável.

As unidades de proteção integral têm objetivo básico de preservar a natureza, sendo admitido apenas o uso indireto de seus recursos naturais, ou seja, uso que não envolva consumo, coleta, dano ou destruição dos recursos naturais.

Preservação da natureza é, de acordo com o artigo $2^{\circ}$, inciso $\mathrm{V}$ do SNUC o "conjunto de métodos, procedimentos e políticas que visem a proteção a longo prazo das espécies, habitats e ecossistemas, além da manutenção dos processos ecológicos, prevenindo a simplificação dos sistemas naturais." (In: MEDAUAR, 2008, p. 983).

Pertencem ao grupo das unidades de conservação de proteção integral Estações Ecológicas, Reservas Biológicas, Parques Nacionais, Monumentos Naturais e Refúgios de Vida Silvestre.

A outra categoria de unidades de conservação são as de uso sustentável onde se incluem as Áreas de Proteção Ambiental, Áreas de Relevante Interesse Ecológico, Florestas Nacionais, Reservas Extrativistas, Reservas de Fauna, Reservas de Desenvolvimento Sustentável e Reservas Particulares do Patrimônio Natural.

Uso sustentável, de acordo com o SNUC é a "exploração do ambiente de maneira a garantir a perenidade dos recursos ambientais 
renováveis e dos processos ecológicos, mantendo a biodiversidade e os demais atributos ecológicos, de forma socialmente justa e economicamente viável." (BRASIL, Lei 9.985/2000, art. 2º , XI).

A categoria de uso sustentável tem como objetivo a conservação da natureza com o uso sustentável de parcela dos seus recursos naturais.

Conservação da natureza, segundo o artigo $2^{\circ}$, inciso II, é:

O manejo do uso humano da natureza, compreendendo a preservação, a manutenção, a utilização sustentável, a restauração e a recuperação do ambiente natural, para que possa produzir o maior benefício, em bases sustentáveis, às atuais gerações, mantendo seu potencial de satisfazer as necessidades e aspirações das gerações futuras, e garantindo a sobrevivência dos seres vivos em geral. (BRASIL, Lei 9.985/2000).

\section{Legislação ambiental relativa às Áreas de Proteção}

\section{Ambiental}

As Áreas de Proteção Ambiental - APA - são, de acordo com a Lei 6.902, de 27 de abril de 1981, unidades de conservação que têm como objetivo assegurar o bem estar das populações humanas e conservar ou melhorar as condições ecológicas locais. $\mathrm{O}$ artigo $9^{\circ}$ da mesma lei determina que o Poder Executivo, resguardando os princípios que regem o direito de propriedade, estabelecerá normas limitando ou proibindo: 
a) a implantação e o funcionamento de indústrias potencialmente poluidoras, capazes de afetar mananciais de água; b) a realização de obras de terraplanagem e a abertura de canais, quando essas iniciativas importarem em sensível alteração das condições ecológicas locais; c) o exercício de atividades capazes de provocar uma acelerada erosão das terras e/ ou um acentuado assoreamento das coleções hídricas; d) o exercício de atividade que ameacem extinguir na área protegida as espécies raras da biota regional. (BRASIL, Lei 6.902/1981, art. $\left.9^{\circ}\right)$.

Esta Lei foi regulamentada pelo Decreto 99.274, de 6 de junho de 1990, através do capítulo II, artigos 28, 29, 30, 31 e 32.

Portanto, as APA são espaços territoriais sujeitos a uma série de leis, resoluções e decretos, além de estarem também sujeitas aos diplomas legais pertinentes nos níveis estadual e municipal.

A APA Petrópolis foi criada pelo artigo $6^{\circ}$ do Decreto Federal $\mathrm{n}^{\mathrm{o}}$ 87.561, de 13 de setembro de 1982. Este decreto dispõe sobre medidas de recuperação e proteção ambiental da Bacia Hidrográfica do Rio Paraíba do Sul, e dentre outras providências, declara a região serrana de Petrópolis como Área de Proteção Ambiental.

O parágrafo $1^{\circ}$, do artigo $6^{\circ}$, determina a proibição da implantação de indústrias potencialmente poluidoras, capazes de afetar mananciais de água; a realização de obras de terraplanagem e a abertura de canais, quando essas iniciativas importarem em sensível alteração das condições ecológicas locais; o exercício de atividades capazes de provocar acelerada erosão das terras ou acentuado 
assoreamento das coleções hídricas; o exercício de atividades que ameacem extinguir as espécies raras da biota regional. (BRASIL, Dec. no 87.561/1982).

A Área de Proteção Ambiental da RegiãoSerrana de Petrópolis, no Estado do Rio de Janeiro, foi delimitada em 1992, através do Decreto Federal n 527 que confirma as restrições determinadas pela Lei 6.902/1981 e acrescenta a proibição do uso de biocidas, quando indiscriminado ou em desacordo com as normas ou recomendações técnicas oficiais.

Esta unidade de conservação, com área de 59.618 hectares, abrange parte dos municípios de Petrópolis, Guapimirim, Duque de Caxias e Magé, sendo que Petrópolis contribui com 68,32\% do seu território, Magé com 16,75\%, Duque de Caxias, 4,54\% e Guapimirim com $10,39 \%$.

A APA Petrópolis engloba, parcial ou integralmente, treze áreas protegidas: Reserva Biológica do Tinguá; Reserva Biológica Estadual de Araras; Área de Preservação Permanente do Alcobaça; Parque Municipal do Taquara; Parque Municipal da Serra da Estrela; Zona de Vida Silvestre de Araras; Zona de Vida Silvestre da Maria Comprida; Estação Ecológica Paraíso; Reserva Particular do Patrimônio Natural El Nagual; Reserva Particular do Patrimônio Natural Fazenda Querência; Reserva Particular do Patrimônio Natural Graziela Maciel Barroso; Reserva Particular do Patrimônio Natural Fazenda Limeira e Reserva Particular do Patrimônio Natural Pedra dos Amarílis. Faz limite com o Parque Nacional da Serra dos Órgãos e com as APA municipais de Xerém e Santana.

O artigo 15 do SNUC define que:

Área de Proteção Ambiental é uma área em geral extensa, com um certo grau de ocupação 
humana, dotada de atributos abióticos, bióticos, estéticos ou culturais especialmente importantes para a qualidade de vida e o bem estar das populações humanas, e tem como objetivos básicos proteger a diversidade biológica, disciplinar o processo de ocupação e assegurar a sustentabilidade do uso dos recursos naturais.

$\S 1^{\circ}$ A Área de Proteção Ambiental é constituída por terras públicas ou privadas. $\S 2^{\circ}$ Respeitados os limites constitucionais, podem ser estabelecidas normas e restrições para a utilização de uma propriedade privada localizada em uma Área de Proteção Ambiental. [...]

$\S 5^{\circ}$ A Área de Proteção Ambiental disporá de um Conselho presidido pelo órgão responsável por sua administração e constituído por representantes dos órgãos públicos, de organizações da sociedade civil e da população residente [...]. (BRASIL, Lei 9.985/2000).

Por estar inserida no bioma Mata Atlântica, a APA Petrópolis é Patrimônio Nacional como determina o parágrafo $4^{\circ}$, do artigo 225 da Constituição Federal. Este bioma é uma das 33 regiões do planeta conhecidas como um hotspot, isto é, uma região de prioridade para conservação. (LUIZ PAULO PINTO et.al., 2006; MMA, 2002; TABARELLI et.al. 2009).

A Mata Atlântica é, também, Reserva da Biosfera. Segundo 
o artigo 41 da Lei 9.985/2000, Reserva da Biosfera é um modelo, adotado internacionalmente, de gestão integrada, participativa e sustentável dos recursos naturais, com objetivos de preservação da diversidade biológica, desenvolvimento de atividades de pesquisa, o monitoramento ambiental, educação ambiental, desenvolvimento sustentável e melhoria da qualidade de vida das populações.

A Reserva da Biosfera da Mata Atlântica, cuja área foi reconhecida pela UNESCO, foi a primeira unidade da Rede Mundial de Reservas da Biosfera declarada no Brasil. Tem como função a conservação da biodiversidade e dos demais atributos naturais da Mata Atlântica, incluindo a paisagem e os recursos hídricos; a valorização da sócio-diversidade e do patrimônio étnico e cultural a ela vinculados; o fomento ao desenvolvimento econômico que seja social, cultural e ecologicamente sustentável; o apoio a projetos demonstrativos, à produção e difusão do conhecimento, à educação ambiental e capacitação, à pesquisa científica e o monitoramento nos campos da conservação e do desenvolvimento sustentável.

\section{Legislação ambiental pertinente à APA Petrópolis}

A população residente na APA Petrópolis está sujeita ao cumprimento de várias determinações legais. São vários artigos de diversas leis nos três níveis administrativos. No Anexo I encontrase a relação da legislação federal especificamente aplicável à APA Petrópolis.

Com foco na conservação da biodiversidade, é importante destacar a Lei 11.428 de 22 de dezembro de 2006, que dispõe sobre a utilização e proteção da vegetação nativa do Bioma Mata Atlântica, tendo em vista que a APA Petrópolis situa-se neste bioma e encontrase inserida nas formações florestais classificadas como Floresta 
Ombrófila Densa Submontana, Floresta Ombrófila Densa Montana, Floresta Ombrófila Densa Altomontana e Campos de Altitude.

Por apresentar remanescentes de vegetação nativa no estágio primário, assim como nos estágios secundários inicial, médio e avançado de sucessão ecológica² ${ }^{2}$, as florestas existentes no território da APA Petrópolis, têm seu uso e conservação regulado pela Lei da Mata Atlântica, como é conhecida a Lei 11.428/2006, de acordo com o com o parágrafo único do artigo $2^{\circ}$.

Esta lei tem por princípios e objetivos o desenvolvimento sustentável, a salvaguarda da biodiversidade, da saúde humana, assim como a proteção das paisagens de valor estético e turístico e, por último, mas não menos importante, a manutenção do regime hídrico. (BRASIL, Lei 11.428/2006, art. $6^{\circ}$ ).

Todos estes objetivos vão de encontro aos motivos que concorreram para a transformação da região onde está inserida a APA Petrópolis num espaço territorial protegido, reafirmando a importância desta unidade de conservação.

Outro ponto importante da lei da Mata Atlântica que reforça o decreto de criação da APA Petrópolis encontra-se no artigo $7^{\circ}$, onde estão elencadas as condições de proteção e uso do bioma. São elas:

$$
\begin{aligned}
& \text { I - a manutenção e a recuperação da } \\
& \text { biodiversidade, vegetação, fauna e regime } \\
& \text { hídrico [...] para as presentes e futuras } \\
& \text { gerações; } \\
& \text { II - o estimulo à pesquisa, à difusão de }
\end{aligned}
$$

2 Sucessão Ecológica: substituição seqüencial de espécies vegetais e animais num ecossistema. Compreende todas as etapas do processo, desde a chegada das primeiras espécies até o máximo desenvolvimento, isto é, o clímax. Quando o processo se refere apenas à comunidade de plantas recebe a denominação de sucessão vegetal. O processo de sucessão permite que o ecossistema se recomponha após sofrer um impacto. (IBGE, 2004). 
tecnologias de manejo sustentável da vegetação e à formação de uma consciência publica sobre a necessidade de recuperação e manutenção dos ecossistemas;

III - o fomento de atividades públicas e privadas compatíveis com a manutenção do equilíbrio ecológico;

IV - o disciplinamento da ocupação rural e urbana, de forma a harmonizar o crescimento econômico com a manutenção do equilíbrio ecológico. (BRASIL, Lei 11.428/2006).

O artigo 14 desta lei dispõe sobre a possibilidade de supressão de vegetação, em caso de utilidade pública e interesse social. Estes deverão ser caracterizados e motivados em procedimento administrativo próprio quando não existir alternativa técnica e locacional ao empreendimento proposto.

É importante ressaltar que utilidade pública e interesse social, de acordo com o artigo $3^{\circ}$, incisos VII e VIII da mesma lei, são:

VII - utilidade pública:

a) atividades de segurança nacional e proteção sanitária;

b) as obras essenciais de infra-estrutura de interesse nacional destinadas aos serviços públicos de transporte, saneamento e energia, declaradas pelo poder público federal ou dos Estados;

VIII - interesse social

a) atividades imprescindíveis à proteção 
da integridade da vegetação nativa, tais como: prevenção, combate e controle do fogo, controle da erosão, erradicação de invasoras e proteção de plantios com espécies nativas, conforme resolução do Conselho Nacional do Meio Ambiente CONAMA;

b) atividades de manejo agroflorestal sustentável praticadas na pequena propriedade o posse rural familiar que não descaracterizem a cobertura vegetal e não prejudiquem a função ambiental da área.

c) demais obras, planos, atividades ou projetos definidos em resolução do Conselho Nacional do Meio Ambiente. (BRASIL, Lei 11.428/2006).

No capítulo VI, a lei remete à proteção do bioma nas áreas urbanas e metropolitanas, o que se aplica diretamente à APA Petrópolis. O artigo 30 diz:

É vetada a supressão de vegetação primária do Bioma Mata Atlântica, para fins de loteamento ou edificação, nas regiões metropolitanas e áreas urbanas consideradas como tal em lei específica, aplicando-se à supressão da vegetação secundária em estágio avançado de regeneração as seguintes restrições:

I-nos perímetros urbanos aprovadosatéa data 
de início de vigência desta Lei, a supressão de vegetação secundária em estágio avançado de regeneração dependerá de prévia autorização do órgão estadual competente e somente será admitida, para fins de loteamento ou edificação, no caso de empreendimentos que garantam a preservação de vegetação nativa em estágio avançado de regeneração em no mínimo $50 \%$ da área total coberta por esta vegetação [...]

II - nos perímetros urbanos aprovados após a data de início de vigência desta Lei, é vedada a supressão de vegetação secundária em estágio avançado de regeneração do Bioma Mata Atlântica para fins de loteamento ou edificações. (BRASIL, Lei 11.428/2006).

Tendo em vista que a maior parte do território desta APA situase no município de Petrópolis e em área urbana, o uso do solo está muito relacionado à implantação de loteamentos, sejam eles oficiais e regularizados ou clandestinos e, conseqüentemente, irregulares, o artigo 31 da Lei da Mata Atlântica determina que:

Nas regiões metropolitanas e áreas urbanas, assim consideradas em lei, o parcelamento do solo para fins de loteamento ou qualquer edificação em área de vegetação secundária, em estagio médio de regeneração, do Bioma Mata Atlântica, devem obedecer ao disposto no Plano Diretor do Município e demais 
normas aplicáveis, e dependerão de prévia autorização do órgão estadual competente [...]. (BRASIL, Lei 11.428/2006).

Portanto, a Lei da Mata Atlântica se torna um instrumento a mais para que os órgãos da administração municipal, assim como o Instituto Chico Mendes, responsável pela administração e fiscalização desta unidade de conservação, possam atuar com fins de evitar maiores danos à fauna e flora, assim como, à paisagem da APA.

\section{Referências}

ANTUNES, Paulo de Bessa. et al. Legislação ambiental do Estado do Rio de Janeiro. Rio de Janeiro: Editora Lúmen Júris, 1999, 625 p.

BRASIL. Constituição da República Federativa do Brasil, de 05 de novembro de 1988. In: MEDAUAR, O. Coletânea de Legislação Ambiental. SP. Editora Revista dos Tribunais, 2008. 1.117 p.

Lei 11.428, de 22 de dezembro de 2006. Dispõe sobre a utilização e proteção da vegetação nativa do Bioma Mata Atlântica e dá outras providências. In: MEDAUAR, O. Coletânea de Legislação Ambiental. SP. Editora Revista dos Tribunais, 2008. 1.117 p.

. Decreto $^{\circ} 2.519$, de 16 de março de 1998. Promulga a Convenção sobre Diversidade Biológica RJ: Editora Gráfica Auriverde, 1998.

Decreto $n^{\circ} 87.561$, de 13 de setembro de 1982. Dispõe sobre as medidas de recuperação e proteção ambiental da Bacia Hidrográfica do Rio Paraíba do Sul, e dá outras providências. Disponível em: 
<www.lei.adv.br/87561-82.htm.> Acesso em: jan. 2007.

Decreto $n^{0}$ 527, de 20 de maio de 1992. Delimitação da APA

Petrópolis. Disponível em: <www.jusbrasil.com.br/legislacao/.../ decreto-527-92>. Acesso em jan. 2007.

BRASIL. Decreto $n^{0}$ 99.274, de 6 de junho de 1990. Regulamenta a Lei 6.902/1981 e a Lei 6.938/1981. In: MEDAUAR, O. Coletânea de Legislação Ambiental. SP. Editora Revista dos Tribunais, 2008. 1.117 p.

Lei $n^{0}$ 6.902, de 27 de abril de 1981. Dispõe sobre a criação de Estações Ecológicas, Áreas de Proteção Ambiental e dá outras providências. In: MEDAUAR, O. Coletânea de Legislação Ambiental. SP. Editora Revista dos Tribunais, 2008. 1.117 p.

Lei $n^{\circ}$ 9.985, de 18 de julho de 2000. Regulamenta o art. 225, $\S 1^{\circ}$, incisos I, II, III e VII da Constituição Federal, institui o Sistema Nacional de Unidades de Conservação. In: MEDAUAR, O. Coletânea de Legislação Ambiental. SP. Editora Revista dos Tribunais, 2008. $1.117 \mathrm{p}$.

INSTITUTO BRASILEIRO DE GEOGRAFIA E ESTATÍSTICA - IBGE. Vocabulário básico de recursos naturais e meio ambiente. Rio de Janeiro: IBGE, 2004, $322 \mathrm{p}$.

INSTITUTO ECOTEMA. Zoneamento da APA-Petrópolis, 2003, 2 CDROM.

MEDAUAR, Odete. Coletânea de legislação ambiental. São Paulo: Editora Revista dos Tribunais, 2008. 1.117 p.

http://www.ucp.br/htmlljoomlaBR/lexhumana/lexhumana.htm 
MINISTÉRIO DO MEIO AMBIENTE. Biodiversidade brasileira avaliação e identificação de áreas e ações Prioritárias para Conservação, Utilização Sustentável e Repartição de Benefícios da Biodiversidade Brasileira. Brasília, 2002.

PAIVA, Julieta Laudelina de. Biodiversidade, legislação ambiental e desenvolvimento socioeconômico em unidades de conservação. 2010. $187 \mathrm{fl}$. Tese (Doutorado em Meio Ambiente) - Programa de Pós-Graduação em Meio Ambiente, Universidade do Estado do Rio de Janeiro, Rio de Janeiro, 2010.

PINTO, LUIZ PAULO. et al., Mata Atlântica Brasileira: Os desafios para conservação da biodiversidade de um Hotspot mundial. In: ROCHA, C.F.D. et al. (org.) Biologia da Conservação: essências. São Carlos: Rima Editora, 2006. Cap. 4, p. 91-117.

TABARELLI, M. et al. The Atlantic Forest of Brazil: endangered species and conservation planning. The Atlantic Forest of South America: biodiversity status, trends and outlook, 2003 apud PINTO, LUIZ PAULO. et al., Mata Atlântica Brasileira: Os desafios para conservação da biodiversidade de um Hotspot mundial. In: ROCHA, C.F.D. et al. (org.) Biologia da Conservação: essências. São Carlos: Rima Editora, 2006. Cap. 4, p. 91-117. 